Running head: Focus in Children's reference comprehension

\title{
Information structure cues for 4-year olds and adults: Tracking eye movements to visually presented anaphoric referents
}

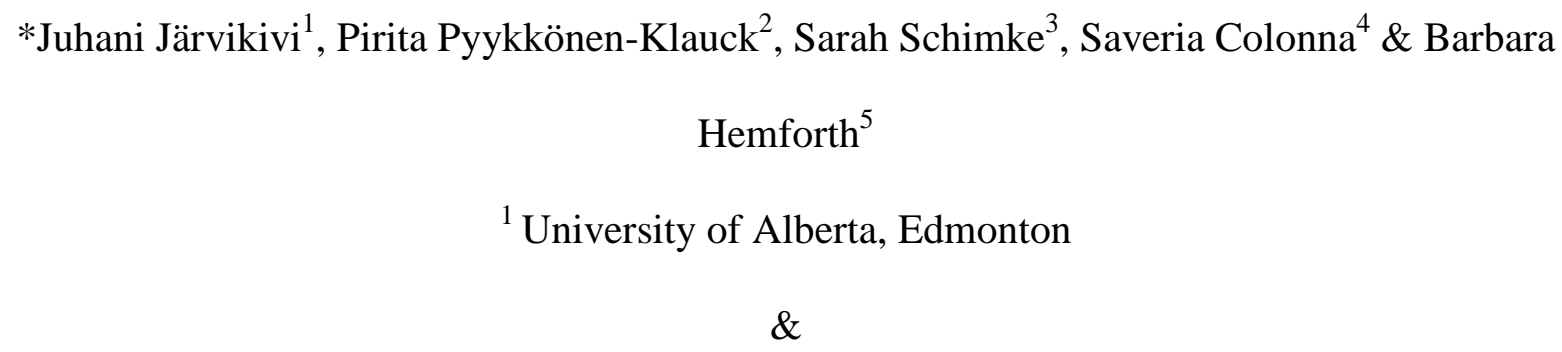

Max Planck Institute for Psycholinguistics, The Netherlands

${ }^{2}$ Saarland University, Germany

${ }^{3}$ Osnabrück University, Germany

${ }^{4}$ University of Paris 8 \& CNRS, France

${ }^{5}$ University Paris Diderot, Sorbonne Paris Cité \& CNRS, France

*Corresponding author:

Juhani Järvikivi

Department of Linguistics

University of Alberta

Edmonton T6G 2E7

CANADA

Tel: (780)-248-1276

Fax: (780)-492-0806

jarvikiv@ualberta.ca 


\section{Abstract}

Studies on young children's online comprehension of pronominal reference suggests that children follow similar syntactic, semantic and discourse constraints as adults. However, the observed effects are less stable and appear much later in the eye movement record than in adults. It is not clear, whether this is because children are cued by a different set of factors than adults; or whether children use the same set of constraints, like subjecthood or firstmention, but the delay is caused by the developmental stage in which these cues are not yet fully acquired. We added an information structure cue (focus) and asked whether it affects syntactically more/less salient discourse referents (subjects/objects) the same way and shows a similar pattern in adults and children or whether it modulates the reliance on syntactic salience in children. Four-year-old German children and adults listened to stories with focused or unfocused syntactically prominent and non-prominent entities, subjects and objects, while we registered their eye movements to visually presented antecedents for ambiguous pronouns. Syntactic and information structural prominence interacted for children: focusing increased the looks to the syntactically salient subject antecedents, but not to the syntactically less salient object antecedents. This suggests that clefting helps children to locate the preferred antecedent. Adults' pronoun resolution in contrast was not modulated by clefting in a clear way. Instead, they showed an overall effect of syntactic prominence. Our study suggests that children and adults are sensitive to the same structural cues in reference resolution and that the time delay results from these constraints being not yet fully acquired. The process may be enhanced, but not modified, with additional cues such as clefts.

Keywords: language comprehension, visual world paradigm, eye-tracking, pronoun resolution, child language, language acquisition, information structure, focus, cleft structures 
A central prerequisite to successful language comprehension is the ability to resolve referential relations. Understanding reference is therefore essential. To understand how the second sentence in (1) relates to the first, people need to decide whether 'he' refers to the fox or the rabbit.

(1) Der Hase kitzelt den Fuchs an dem Bergsee, als er gerade an etwas ganz besonders lustiges denkt (lit.: The rabbit tickles the fox at the mountain lake, when he just about something particularly funny thinks; 'The rabbit tickles the fox at the mountain lake, when he is just thinking about something particularly funny')

As the flow of information in speech unfolds fast in time, listeners are forced to make such decisions rapidly. Regardless of (abundant) ambiguity children seem to be able to create an event model of what is described in this situation and correctly interpret and produce pronouns in felicitous context already around four years of age and show adult-like overall comprehension profile across a large variety of contexts around six (e.g., Matthews, Lieven, Theakston, \& Tomasello, 2009; for a review, Conroy, Takahashi, Lidz \& Phillips, 2009). Furthermore, they show many adult-like preferences in online processing already at 3 years of age (e.g., Pyykkönen, Matthews, \& Järvikivi, 2010). How exactly children end up selecting the intended antecedent, and especially, how and when children learn which cues to follow given the time constraints of normal conversation is not only a challenge to current theories of reference resolution but can also shed light on the general path of how reference is acquired. Moreover, studying how the developing system deals with different sources of information during online processing might also give us insights into the adult system. On the one hand, if the use of certain cues develops very late and can thus not be observed in young children, this might be taken as an indication that these cues are less important for and perhaps less constitutive of the adult system as well. One might then predict that adults would 
for example rely less on these cues when under cognitive load, or that these cues could be more easily overridden by other cues than is the case for cues that appear early in development. In this vein, studies in language attrition, for example, suggest that rules that are learned late tend to be more fragile and get lost early (e.g., Kiijzer, 2007). On the other hand, children's behaviour might also give us insight into the function of cues that might be hard to study in the more efficient adult system. As argued by Snedeker and Trueswell (2004), it is possible that adults react to some cues, but have become so fast in discarding them when more important cues are present that their influence can no longer be observed. Children might be slower in weighting different cues, and this might give us a more detailed insight into what is the influence of each cue present in a given situation.

In the domain of reference, the influence of different cues in the comprehension system has been studied in particular with respect to pronoun resolution. Pronouns are a shortcut means to refer to entities that are highly active in listeners' discourse models or in listeners' focus of attention and thus easily accessible or available to be picked up as an antecedent (Gernsbacher \& Hargreaves, 1988; Gernsbacher, 1990; Gundel, Hedberg, \& Zacharski, 1993; Foraker \& McElree, 2007 for a discussion). Processing studies have shown that adults' perception of referent salience is affected by general principles, like subjectagenthood and/or being first-mentioned in many languages (e.g., Arnold, Eisenband, BrownSchmidt, \& Trueswell, 2000; Carreiras, Gernsbacher, \& Villa, 1995; Gernsbacher \& Hargreaves, 1988; Gernsbacher, Hargreaves, \& Beeman, 1989; Järvikivi, Van Gompel, Bertram, \& Hyönä, 2005; MacWhinney, 1977; McDonald \& MacWhinney, 1995; however, see Hemforth, Konieczny, Scheepers, et al., 2010, for crosslinguistic differences). These preferences, however, can be rapidly modified and even overridden by discourse, semantic and event properties like verb causality (e.g., Kehler, 2002; Koornneef \& Van Berkum, 2006; 
MacDonald \& MacWhinney, 1995; Pyykkönen \& Järvikivi, 2010; Van Berkum, Koornneef, Otten, \& Nieuwland, 2007).

Recent visual world experiments in which children's eye movements to referents are recorded during online spoken language comprehension suggest that children may be affected by similar constraints for structural and semantic prominence of antecedents as adults. Song and Fisher $(2006,2007)$ found that 2- and 3-year-olds treated pronouns as co-referential with the subject/first-mentioned referent in the prior context (cf. Arnold, Brown-Schmidt, \& Trueswell, 2007; Arnold, Brown-Schmidt, Trueswell, \& Fagano, 2005). Hartshorne, Nappa and Snedeker (2010) showed that English speaking 5-year-old children resolved the pronoun he towards the first-mentioned antecedent. As in the previous studies (Song \& Fisher, 2005; Hartshorne et al., 2010), Pyykkönen, Matthews and Järvikivi (2010) found that English threeyear-old children's preference for first-mentioned subject antecedents appeared in the eye movement record only fairly late compared to adults, $1200 \mathrm{~ms}$ after the onset of the pronoun he in contexts such as The panda hit the parrot near the hut. Do you know what happened next? He... Pyykkönen et al. (2010) further showed that children's attention to the discourse referents was rapidly modulated by semantic prominence, namely, whether the subject and object arguments of the verb had more or less prototypical agent and patient properties, as with hit (highly prototypical agent- and patient-like properties) compared to tease (less prototypical agent- and non-prototypical patient-like properties). Importantly, the semantic and structural prominence interacted: Object, but not subject antecedents, were affected by agent-patient prototypicality: Children fixated more often on the objects of high (hit) than low (tease) transitive verbs suggesting that the degree to which the object would be affected by the action modulated children's pronoun resolution preferences. Finally, Sekerina, Stromswold and Hestvik (2004) showed, in an eye-movement study comparing the processing of reflexive and personal pronouns, that 4-7 (average 6;6) year old children were 
equally likely ( $90 \%)$ to choose the sentence-internal picture showing a box behind a boy's back (and a man facing the box) with pronouns and reflexives when asked to "point to the picture where the boy has placed the box behind him/himself". Even though the eye movements showed more fixations to this picture in the reflexive condition, the children were still considerably slower than adults in fixating the preferred antecedent. A recent study by Clackson, Felser and Clahsen (2011) showed, however, that slightly older, 6-9 year-old children were adult-like in terms of the timing of the effects, indeed also showing the preference for first-mentioned subjects rapidly about $400 \mathrm{~ms}$ after hearing the pronoun.

Thus, available studies suggest that young children show sensitivity to structural and semantic constraints that at least at the outset appear to be similar to adult preferences. However, when structural and semantic effects are found in young children's (younger than 6) pronoun resolution, they usually appear much later than in adults' in the eye movement record. This observation may be related to other differences in children's and adults' processing observed in this age group.

A series of studies have investigated young children's processing of garden path sentences, e.g., cut the cake with the candle, where the initially preferred interpretation of a sentence has to be revised in the light of further incoming information (Choi \& Trueswell, 2011; Kidd, Stewart, \& Serratrice, 2011; Snedeker \& Trueswell, 2004; Trueswell, Sekerina, Hill, \& Logrip, 1999; Weighall, 2008). These studies have shown that like adults, 5-year-old children are strongly influenced by lexical biases when processing these types of sentences. In contrast to adults, however, children seem to be much less sensitive to the influence of the visually presented referential context and, instead, rely on linguistic information in their parsing strategies, even to the extent that they are unable to revise their initial interpretation when faced with clearly contradictory information. 
Focus in children's reference comprehension

The question becomes whether children are sensitive to the same constraints as adults and whether their observed inability to benefit from some cues is due to how reliable these cues are in a language or due to limitations in children's cognitive capacity. For example, children might rely solely on highly reliable cues, such as bottom-up lexical biases, while the use of less reliable cues, as the referential context, might be acquired later (Snedeker \& Trueswell, 2004). It is also possible, however, that the inability to take into account the referential context in these studies is due to a general cognitive difficulty that children might have with revising initial interpretations. This process makes it necessary to hold both the initial and the revised representation in working memory. Possibly due to their less developed capacities for cognitive control, children might have particular difficulties with this process, and a strong tendency to stick to the initial interpretation (e.g., Choi \& Trueswell, 2011; see also Novick, Trueswell, \& Thompson-Schill, 2005 for a discussion of the cognitive control constraints also with adult comprehenders). Furthermore, Pyykkönen and Järvikivi (2012) suggested that children have difficulties specifically in creating and modifying situation models on the fly. According to this account, children do in principle use the same cues as adults, but might use them less efficiently due to either cognitive limitations or inability to select the reliable cue or because of some combination of the two. This is in line with the pronoun resolution studies summarized above, as well as with other studies showing that even young children are able to correctly interpret some complex cues on the discourse level such as intonation used to indicate speech acts (Zhou, Crain \& Zhan, 2012).

Thus, the observed differences among adults and children could have multiple sources: One possibility is that, despite the apparent similarity, children could be cued (partly) by various sources of information some of which could be different from the constraints by which adults are mainly guided. That is, children might in fact have to deal with and consider more rather than less cues than adults, possibly because they have not yet 
figured out the importance of different cues in different situations. For example, assuming that in the case of prototypical personal subject pronouns, like German er or English he, adult resolution would first and foremost be guided by order-of-mention and/or syntactic/thematic information, i.e., finding the first-mentioned and/or grammatical agent-subject antecedent of the local or immediately preceding context; it could be that children were less clear about their preferences and therefore would be cued also by additional sources of information, for example individual verbs or agents of the event. These additional cues would then make the subject antecedent less readily available and forming the link with the subject less probable, resulting in later observable effects than in adults. In contrast to the above, however, it could be that children are sensitive to and consider the same sources of information, but might not be as efficient as adults to discard the ones that are not relevant for the task at hand. For example, children might follow subjecthood and first-mention to guide their resolution choices, but these constraints might not yet be stabilized to the extent that the preferred antecedent would be available as readily as in adults. That is, rather than considering additional cues, children would just need additional time to establish the balance between the different sources of information.

One way to advance answering this question is to investigate whether other sources of information, for example information structure devices such as focus, can modulate the subjecthood and first-mention preferences, and importantly, whether the relative impact of focus on comprehension of reference shows a similar pattern in adults and children or whether children consider focus as an additional cue leading to modified reliance of grammatical role and order-of-mention as cues compared to adults. The investigation of focus is thereby of particular relevance because compared to subjecthood or order-of-mention, its impact on pronoun resolution should arguably be much harder to acquire for children. While the antecedent of virtually every pronoun needs to fulfill a grammatical role and have a 
position in the sentence, not all pronouns occur in the context of explicit focusing devices like cleft structures. This is the case for $i t$-clefts in German, which are relatively less frequent - at least in written corpora - compared to Romance languages (Dufter, 2007). There are thus fewer occasions where children could learn about the meaning of focus devices and their impact on pronoun resolution. If they nevertheless were sensitive to this device in the same way as adults, this would provide a strong case for the idea that the child comprehension system is very similar, and that differences might be due to cognitive limitations.

In the following, we will first summarize the literature on the role of clefting in adult pronoun resolution, and then turn in more detail to the studies on child pronoun resolution conducted so far.

\section{The role of clefting in pronoun resolution}

A frequent focusing device is syntactic clefting (2):

(2) Es ist der Hase, der den Fuchs kitzelt an dem Bergsee, als er gerade an etwas ganz besonders lustiges denkt (It is the rabbit who tickles the fox at the mountain lake, when he just about something particularly funny thinks).

Although there is no unified account of focus realizations and interpretations in the linguistic literature (see e.g., Dufter, 2007, for clefting in Romance and Germanic languages; É. Kiss 1998, for a discussion on the interpretation of it-clefts in English), we can assume that clefting is usually taken as a means to express informational or contrastive focus; e.g., the rabbit in (2) can be taken as the answer to "Who is tickling the fox?" (Carpenter \& Just, 1977; Chafe, 1976). Even though there is some variability with respect to the use of cleft structures across languages, some commonalities have been advocated. Hedberg (in press) assumes a bipartition of cleft sentences with the clefted part expressing exhaustive focus (It was the rabbit (and nobody else) who tickled the fox). Following Krifka (2007), the function 
of focus expressed here is that of indicating the presence of alternatives relevant for the interpretation of the linguistic expression. The cleft picks out only one of the alternatives. ${ }^{1}$

Research has shown that such focusing can modulate adult listeners' attention to the focused entities in the event; their memory representations, and the ease of integration of that information into previous discourse (Birch, Albrecht \& Myers, 2000; Almor, 1999; Foraker, 2004; Hornby, 1974; Zimmer \& Engelkamp, 1981; Sturt, Sanford, Stewart \& Dawydiak, 2004; Ward \& Sturt, 2007; Zimmer \& Engelkamp, 1981; Birch \& Garnsey, 1995; Birch \& Rayner, 1997; Singer, 1976). Clefting has been shown to increase the ease of reference resolution as reflected in decreased reading times when a noun phrase refers to a clefted referent (Almor, 1999; Foraker, 2004) and the probability of successful retrieval of an antecedent (Foraker \& McElree, 2007). As comprehenders must build a mental representation of the discourse by inferring how the events described in the discourse have occurred (for situation models in language comprehension, see e.g., Zwaan, 2004; Zwaan \& Madden, 2004; Zwaan \& Radvansky, 1998; Barsalou, 1999), one could expect that when two events, as in (2) above, are coordinated into one mental representation, this integration and the computation of a discourse/situation model are influenced by the prominence of the mentally represented discourse entities in the first utterance and, thus, by clefting (e.g., Gernsbacher, 1990; Pyykkönen \& Järvikivi, 2012; Zwaan \& Radvansky, 1998).

While the influence of focus in adult pronoun resolution has attracted some attention, the available evidence of the function of clefting is inconclusive. Arnold (1999) found that when instructed to continue the discourse after preambles like, Ron was looking through his address book, trying to make up his mind. He had an extra ticket to the opera, but he didn't know which friend to invite. The one he decided on at last was Kysha / Fred (clefted) vs. At last he decided on Kysha / Fred (nonclefted), participants used pronoun continuations to refer mainly to subject antecedents even when the object was clefted. Cowles and colleagues, in 
turn, (2007) found that subjecthood facilitated participants' naming latencies over object referents in cross-modal priming, but it-clefted subjects did not have an advantage over nonclefted topical subjects, whether repeated (discourse topic) or mentioned only once (sentence topic). They suggest that even though both cleft focus and topicalization alike increased the likelihood of resolving the pronoun towards the clefted and topicalized referents, clefting did not increase the activation of the focused referent vis-à-vis topicalization. In contrast to this, Colonna, Schimke and Hemforth (2012) observed, in German and French offline data, different effects of topicalization and focusing: while topicalized referents were generally preferred in the case of pronouns appearing in a subordinate clause of the same sentence, this was not the case for focused referents, where no clear effect could be observed. In particular, focusing the object did not override the general subject-preference found in the German data of this study.

Finally, Kaiser (Exp 2, 2011) investigated the effects of contrastive focus in adult reference resolution by contrasting subject and object clefts (It was John that he congratulated vs. It was John who congratulated him) to nonclefted SVO structures (He congratulated John vs. John congratulated him) preceded by a context sentence I heard that Greg congratulated Mike.... She found that clefted, as compared to nonclefted structures, did not increase participant's offline choices for a referent, regardless of whether the clefted referent was the subject or the object. However, the subsequent eye movement study showed marginal effects of clefting as manifested in a late interaction $(1502-2000 \mathrm{~ms}$ from pronoun onset), indicating increased fixations to focused subjects compared to other conditions. Kaiser's (2011) results suggest that contrastive focus had an effect for subjects but not for objects, possibly, as she suggests, because clefting may have enhanced the prominence of the subject antecent or because clefted subjects are more marked than clefted objects (for processing of marked structures, see e.g., Jaeger \& Snider, 2008). 
Even though the evidence is not conclusive, it is safe to conclude that the effects of cleft structures in adult pronoun comprehension are confined to subject antecedents. This implies that in adults the first-mention/subjecthood principle constrains resolution to the extent that it neither leaves much room for increased availability for subjects nor is able to override the subjecthood constraint when the less salient (object) antecedent is clefted. If clefting does have an observable effect, it will be to further facilitate the referential link to the already salient (first-mentioned) subjects.

However, it is not known whether young children are sensitive to focusing and whether they would use this information in the similar manner as adult language users. In our experiments, we will ask whether the specific processes and functions attributed to clefting are already in place for young children. First, we are interested in whether children's pronoun resolution preferences are affected by cleft structures or whether they show sensitivity to these at all. Secondly, We are interested in the question of whether children at the age of four are already sensitive to focusing in a principled way, i.e., whether in children focusing affects more and less salient antecedents in terms of their grammatical roles, e.g., subjects and objects differently, as it does for adults, or whether children do not differentiate between the antecedents in the same way.

\section{Present study}

We inspected the effects of focusing on 4-year-old children's online pronoun resolution in spoken German using the Visual World eye-tracking paradigm (Arnold et al., 2000; Järvikivi et al., 2005; Pyykkönen et al., 2010). Children heard mini-stories depicting two animal characters acting out familiar transitive verbs. As we were concerned that still images with transitive action, e.g., tickling, might be harder for children to imagine, we used animated video clips showing the action mentioned in the discourse. Children's eye 
movements were tracked time locked to the onset of the ambiguous pronoun er 'he'. We used cleft structures, fronting either the syntactically salient (subject) or non-salient (object) antecedent, which we compared to non-clefted SVO and OVS sentences, respectively (Table 1). In order to have a reference to the fully matured system, the experiment was administered to an adult control group as well. If focusing modulates the prominence of the entities in Es ist der Hase, der den Fuchs kitzelt 'It is the rabbit (subj), that the fox (obj) tickles', it should affect the likelihood with which this entity is chosen as the antecedent of er in als er gerade an etwas ganz besonders lustiges denkt 'when he just about something particularly funny thinks'. Earlier research on children's (ambiguous) pronoun resolution and syntactic ambiguity resolution suggest that children use the same information as adults to arrive at a preferred interpretation and any differences are due their greater inability to weigh the relative importance of the cues and/or difficulty to revise their initial syntactic parses or situation models on the fly. This account would predict that, crucially, we should observe at least a sensitivity to focusing which would interact with the grammatical role of the focused antecedent as has been observed in adults. If, however, we assume that children either do not (yet) use focus as a cue or they use also additional information, we should observe a pattern that differs from adults and that does not show the above asymmetry with focus and grammatical role.

Method

\section{Participants}

Altogether 39 mono-lingual German-speaking 4-year-olds (19 girls; mean age 4;4, range 3;11-5;0) in Kindergartens in Kleve and Kranenburg in Germany, and 24 native German undergraduates at Saarland University completed the experiment. Seven children were excluded because they did not complete the test (2) or there was over 50\% track loss 
due to excessive moving during the experiment. Parental consent was obtained for the children prior to participation. Adult participants gave written consent. Children received a certificate and adults 5 euros in exchange of their participation.

\section{Materials}

Thirty mini-stories were created, 20 for experimental and 10 for filler materials, using familiar transitive action verbs and 15 pairs of familiar depictable animal characters. Each verb and character was used twice, so that all characters had the role of subject and object across items (animal characters and verbs are listed in Appendix A). 14 of the animal pairs in Pyykkönen et al. (2010) were used, and the videos were animated. Because all experimental animals were required to have the same grammatical gender (masculine), one of the original pairs was replaced by a new one (Wal 'whale' - Biber 'beaver'). ${ }^{2}$ The first sentence introduced the characters (Table 1). The second sentence introduced the critical context clause and a location, followed by a subclause that always began with als 'when' followed by the ambiguous pronoun $e r$ 'he'. In the critical main clause either SVO or OVS word order was used, and the first-mentioned subject or object was either clefted or not. In addition, the order of the characters was counterbalanced so that the first character of the critical sentence was mentioned either first or second in the introductory sentence. The location was used in the second sentence prior to the pronoun in order to attract eye movements away of the potential antecedents before $e r$. The last sentence/scene, which was of no interest in the experiment, mentioned/showed the subject or the object character (counterbalanced), both of the characters, or the location. The stories were read by a female German speaker in a sound treated chamber and recorded onto a computer hard disk. 
-- Please, insert Figure 1 about here --

Experimental video clips were constructed as follows (Table 1, Figure 1): The first scene with the two animals in the left and right corner (upper or lower) and the location in the middle (up or down) was shown for $1000 \mathrm{~ms}$ followed by the first (introductory) sentence allowing for a short preview of the objects prior to the auditory stimuli. $800 \mathrm{~ms}$ after the first sentence, the critical clause was heard and an animation of the described action was simultaneously shown on the screen. The video was aligned with the sound in such a way that the animated action started with the onset of the critical clause and ended $200 \mathrm{~ms}$ after the offset of the second NP, therefore coinciding with the onset of the Adverbial Phrase describing the location. $800 \mathrm{~ms}$ after the adverbial phrase, the clause with the pronoun started. It was followed by a pause of $1600 \mathrm{~ms}$ after which the last sentence was played. With the counterbalancing condition, there were 8 versions of each experimental clip. In the animation, both animals moved toward the centre of the screen (a continuum from image A to image B in Figure 1), the agent-subjects performed the actions by moving their body parts (e.g., a paw to tickle the other animal, image B), after which both animals returned to their original places (corresponding to image A again). Even though the patient-objects of the action also moved towards the centre and returned to their original position, they did not show any specific object-like properties or overt signs affectedness by the actions. Thus, at the onset of the mentioning of the location, both animals quickly returned to their original places (image A), such that eye movements to the animals could be unambiguously detected starting already before the onset of the pronoun and following the pronoun until the end of the sentence. In other words, when the participants heard the pronoun the animals had returned to their original positions and were both present on the screen (image A). Finally, 
image $\mathrm{C}$, appearing during the last sentence that was irrelevant to our experiment, presented either of the two animals, both of them, or the location.

\section{Design and procedure}

Children were tested individually at their Kindergarten. After a short introduction, the children were placed about $50 \mathrm{~cm}$ from the eye tracker screen and the experimenter sat either on their left or on their right (counterbalanced between participants). The children were first shown the characters on the computer screen one by one and asked to name them. In the rare occasion that they named the character incorrectly, they were reminded of the name. When they had seen all the animals they were told that they would be watching short videos of the animals.

Each child was presented with all 30 stories from one of the eight lists. The lists were created so that each list began with two additional practice items. Filler items were also interspersed after one, two or three experimental videos. The order of the filler items was the same on all lists, whereas the order of the 20 experimental videos was randomized for each participant within the remaining position slots. After each video a grey blank screen was shown. The next video was started when the child looked at the star at the centre of the screen.

Adult participants were tested individually in an experimental laboratory. The procedure was as above; except that the experimenter was sitting behind the participants, not next to them.

A Tobii T120 eye tracker was used. Registration was binocular with a $120 \mathrm{~Hz}$ sampling rate and had better than 0.5 degrees spatial accuracy. 


\section{Results}

Based on the object locations, the target area coordinates for subject and object characters were identified. Based on these coordinates, we were able to identify whether participants were looking at the subject, the object or at some other part of the screen in 20 ms time segments. We then aggregated the 20 time segments into $200 \mathrm{~ms}$ windows for analysis starting from the time window of $200 \mathrm{~ms}$ prior to the pronoun onset to $2000 \mathrm{~ms}$ after the onset. In order to inspect overall patterns in the eye movement data, statistical analyses were first carried out for the aggregated number of looks in the whole time window from 200-2000 ms after the pronoun onset using Group (children, adults), Grammatical Role (subject, object) and Focus (cleft, noncleft) as fixed-effects predictors, i.e., comparing firstmentioned focused subject and first-mentioned focused object antecedents to unfocused firstmentioned subject (in SVO) and object (in OVS) antecedents (Table 1). Children's data was then analysed further in three consecutive $600 \mathrm{~ms}$ time windows in order to inspect changes in the preferences over time in more detail ${ }^{3}$. In Figure 2 (panels A-D), we present the effects as percentages of trials on which participants looked at the critical characters for the factors Grammatical Role (subject, object) and Focus (cleft, noncleft).

We conducted Poisson regression analyses for time segment counts using generalized linear mixed-models (lmer and Poisson family in R). Participants and items were treated as a crossed-random effect in order to accommodate by-subject and by-item variation in one model (Baayen, 2008; Barr, 2008; Jaeger, 2008). Model comparison was done using the function anova in $R$. To make sure that the effects observed for the fixed-effects predictors reflect the slopes for those effects and are not due to between-subject and -item variance we further assessed the effect of by-subject and by-item random slopes for each of the fixedeffects predictors (e.g., Baayen, 2008). Including random slopes for antecedent salience significantly benefitted the model fit for all reported models (log likelihood test using the 
function anova in R). The results from the models with the best fit to the data are shown in Tables 2 and 3; Model estimates (regression coefficients), Wald z-scores, and p-values based on z-statistics are reported for the fixed effects.

\section{Statistical analysis}

Model comparison (anova in $R$ ) showed that including interaction terms for the fixedeffects predictors significantly increased the model fit. The model with the best fit to the data is shown in Table 2. The model showed no main effects for any of the fixed-effects predictors. However, there was a significant two-way interaction between Grammatical Role and Focus and Grammatical Role and group and a three-way interaction between Participant Group, Grammatical Role and Focus. Visual inspection of Figure 2 shows that the adult participants showed a clear preference for the subject antecedent and were little if at all affected by focusing either the subject or the object antecedent. However, Figure 2 also shows more looks to the non-cleft subject antecedent already before the pronoun onset with adults. We will return to this below. Children, on the other hand, show more varied effects: as the statistical analyses and Figure 2 suggest, children showed an effect of whether the antecedent was focused or not but, interestingly, this effect was confined to subject antecedents alone. In order to further inspect the children's data, we ran analyses for three consecutive $600 \mathrm{~ms}$ time segments starting $200 \mathrm{~ms}$ after the onset of the pronoun. ${ }^{4}$

-- Please, insert Table 2 about here --

Child data in detail. Table 3 presents the summary of the model parameters for the models with the best fit to the data 200-800, 800-1400, and 1400-2000ms after the onset of the pronoun. The analyses showed that the children were affected by clefting in all time 
windows, even though the effect in the last one was only marginal. Interestingly, however, the models indeed confirmed that in the first two time windows the effect of focus was confined to subject antecedents alone: In other words, children looked more at the focused than unfocused antecedent when it was already salient in the previous discourse than when it was not. Additionally, there were more looks to the object than the subject antecedents overall in the first time window. However, as Figure 2 shows, the looks to object antecedents reach asymptote fairly early (about 400ms from the onset of the pronoun) and thus this early effect points to a general influence of raising the object antecedent in the first position that affected their attention to these referents early on rather than an effect resulting from resolving the ensuing pronoun. Unlike in adults, we found no main effects of the grammatical role of the antecedent within the first $2000 \mathrm{~ms}$ from the pronoun onset for children. ${ }^{5}$

-- Please, insert Table 3 about here --

Adult data in detail. At first sight it would seem that, unlike for children, focus did not affect adults' eye movement behaviour at all. However, Figure 2 (panel B) could be taken to suggest otherwise; namely, that the apparent baseline difference between the subject antecedents might hide the effect and focusing may have affected the rate of the increase in the looks to the subject but not to the object antecedents. We inspected this possibility statistically as follows: In order to increase granularity but at the same time avoid the problem that short time windows are more susceptible to effects due to the contingent nature of eye movements, we calculated the relative rate of change for short consecutive, time windows in $400 \mathrm{~ms}$ steps (0-400 to $1600-2000 \mathrm{~ms})$ using the following formula:

$$
\frac{(P t 2-P t 0)-(P t 1-P t 0)}{t 2-t 1} \times|P t 2-P t 1|
$$


The formula calculates the rate of change for a given condition as the difference of the proportion $(P)$ of the baseline $(t 0)$ corrected slope of change in fixations in two consecutive time windows $(t 1, t 2)$, by multiplying and thus weighting it with the magnitude of the absolute change in those windows (i.e., the absolute value of the difference in the proportion of looks between the two time windows). The baseline used here was the proportion of fixations in the time window $-200-0$ for the condition in question. For example, to get the rate of change between time windows $0-400$ and $400-800 \mathrm{~ms}$ for the cleft subject antecedents, we calculated the rate of change for each observation per time window by subtracting from it the fixations in the baseline time window. After that these baseline weighted proportions of observations in window t1, 0-400ms, were subtracted from those in window $\mathrm{t} 2,400-800 \mathrm{~ms}$, and the result was multiplied with the absolute value of the relative change in the two time windows. After having determined the respective values for the remaining conditions, we modelled the rate of change in each time window using linear mixed effects models with Focus and Grammatical Role as fixed-effects factors and participants and items as a crossedrandom factor. By-subject and by-item random slopes for the fixed-effects predictors did not have an effect on the model fit $\left(\log\right.$ likelihood tests, all $\left.\mathrm{X}^{2}<1\right)$ and thus $p$-values were estimated from t-statistics using the Markov-Chain Monte Carlo simulations with 10000 iterations in R (pvals.fnc in languageR; Baayen, 2008).

The results showed no effect of focus in any of the time windows $(t \mathrm{~s}<1.06, p \mathrm{~s}>$ 0.28). The fixations to subject antecedents increased significantly more than fixations to object antecedents during the first $400 \mathrm{~ms}$ from the pronoun onset $(0-400 \mathrm{~ms})$ and 1400 $1600 \mathrm{~ms}$ (Estimate $=0.460, t=2.33, p M C M C=0.0200$; Estimate $=0.497, t=2.01$, $p M C M C=0.0454$; respectively). There was an interaction in the 800-1200 time window showing more fixations to focused than nonfocused subject antecedents (Estimate $=0.704$, $t=2.13, p M C M C=0.0333)$. There were no significant effects in the last $(1600-2000 \mathrm{~ms})$ 
window $(t \mathrm{~s}<1)$. In summary, if we take into account the rate of change in the eye movement data, it suggests that there may be an effect of focus for the subject antecedents but no effect for the objects, like in the child data. However, this effect was fairly fleeting, appearing only in a single (relatively late) time window.

\section{Discussion}

The current study investigated whether information structure, in particular focusing, affects young children's online resolution of reference. More precisely, we asked (i) whether linguistic focus, realized as cleft structures, would enhance antecedent salience, (ii) whether this would modulate children's online reference resolution pattern, (iii) and whether focusing, would interact with syntactic/thematic role preferences for antecedents. We furthermore wanted to know (iv) whether children's online resolution processes of these structures pattern with those of adults.

Our study provided affirmative answers to the first three of these questions and a partly negative one to the last. The results showed that both syntactic/thematic information and focusing by clefting, affected children's online pronoun resolution preferences. As in previous studies (Song \& Fisher, 2006, 2007; Pyykkönen et al., 2010; Hartshorne et al., 2010) children preferred the subject antecedent, even though this effect appeared, again, very late for non-clefted subjects (see footnote 4; cf. Arnold et al., 2007). More importantly, grammatical role and information structural prominence interacted: in children, focusing increased the looks to the subject antecedents, whereas it did not affect the attention to the object antecedents.

Adult data differed from the child data. Adults showed an early preference for the subject antecedents in both the focused and the non-focused conditions. Neither the timing nor the magnitude of the subject preference in adults was affected by focus in any 
straightforward manner. As in many of the earlier pronoun resolution studies (e.g., Cowles et al., 2007; Kaiser, 2011), there was no clear indication that the strength of the preference would have been modulated by focus, as it was the case for children (cf. Foraker \& McElree, 2007), even though the subsequent growth rate analyses showed a late fleeting effect whereby the looks to the focused subjects increased more rapidly than looks to the nonfocused subjects $(800-1200 \mathrm{~ms})$ relative to the respective baseline.

Apart from the clearer effect of clefting on the subject antecedents, the children differed from adults in other respects: Children's eye movement data revealed an early object preference in the first time window (200-800ms). It could be that this effect reflects the overall increased attention to the objects, because they were mentioned in the (marked) firstposition of the sentence. However, it might be that the early preference for the objects in children also reflects the nature of the object antecedents in transitive events like the present ones (Hopper \& Thompson, 1980; Dowty, 1991). Pyykkönen et al. (2010) showed that threeyear-old English children's pronoun resolution preferences were modified shortly after the onset of the ambiguous pronoun he by whether the verb describing the event was low or high transitive, like see vs. kick, respectively. Children looked more to the object antecedents of a high transitive than low transitive verbs starting already 700ms after they heard the pronoun, suggesting that the degree to which the object was affected by the action modulated children's attention to the characters in the event. Even though some of the verbs used in this study maybe more prototypically transitive than others, all were highly transitive typical agent-patient verbs. As in Pyykkönen et al. (2010), this should increase the salience of objects and might well have contributed to the early object preference. Moreover, because animated (visual) actions were used in the present study, this may have further directed attention to the object characters and added to their salience. However, due to counter- 
balancing, the same verbs were used in both focused and unfocused conditions and should thus not have affected the differences between the conditions.

\section{Adults' and children's pronoun resolution}

Adult studies suggest that focus may increase the ease of reference resolution (Almor, 1999; Foraker, 2004). This could explain the focus effect found in our child study, indicating that 4-year-old-children would be adult-like in this respect in their sentence comprehension. However, the question remains why such an effect was not found in the adult study then. First, this result is in line with the findings of Cowles et al. (2007) and Kaiser (2011), neither of which found a clear effect of focused over non-focused subjects in adults, and with Arnold (1999) who did not find an effect on objects. Partly this may be, as Kaiser (2011) notes, because subject clefts are more marked than object clefts (see below) (see also Jaeger \& Snider, 2008). A further factor that might make it hard for effects of clefts to become visible in particular in the adult data, might be that the adult system is already tuned to interpreting certain pronouns as referring to the syntactically salient subject/first-mentioned entity. In other words, first-mentioned subject antecedents may already be salient and stable enough for the system to make the relevant link so quickly and efficiently that the effect of focus might not be able to appear (statistically) earlier or in a more pronounced way, even if present (e.g., Almor, 1999; Foraker, 2004; Foraker \& McElree, 2007). As German personal pronouns are strongly coreferent with the preceding subject (Bosch, Katz, \& Umbach, 2007; Bouma \& Hopp, 2007; Colonna et al., 2012; Ellert, 2010), this basic preference might not have left room for the focus effect to become visible. Also, clefting in German and in other languages has discourse functions other than focusing (e.g., Lambrecht, 2001), is textually less frequent than in English (e.g., Fischer, 2009), and is not the only a means of focusing in German, where focus is frequently expressed prosodically (e.g., Sauermann, Höhle, Chen, \& Järvikivi, 
2011). Whether prosodic focus would have a qualitatively comparable but stronger effect in adults remains to be determined in future studies.

In pronoun resolution, 3-5-year-old children have already been shown to use morphosyntactic (gender) information (Arnold et al., 2005) and exhibit an adult-like subject/first-mention preference; though it takes them longer to show the effect (Hartshorne at al., 2010; Pyykkönen et al., 2010; Song \& Fischer, 2005, 2007). It is, however, not clear what the source of this delay may be. We will discuss two possible scenarios.

First, it is possible that the observed delay in the effects in children reflects a stage in acquisition where children are already sensitive to adult-like constraints, but these are not yet stabilized to a similar extent. Thus, it may be that probabilistic constraints like subjecthood in German take longer to establish than more reliable cues like grammatical gender, which children seem to pick up fairly early and which affect processing fairly rapidly (Arnold et al., 2007; Hartshorne et al., 2010). This would assume, in line with Foraker \& McElree (2007), that the delay in the time course for these effects would reflect weaker availability and therefore decreased probability that the correct referential link is established. Hence, as children get more and more experienced with the probabilistic constraint, this link would become more stable and the effects would show up earlier in the time course of sentence processing. The observed effect of focus in children, but not in adults, is in line with this view as well. Moreover, as focus had an effect of facilitating the retrieval of subject but not object antecedents, it further suggests that the first-mention/subjecthood constraint is in place already by the age of four - even if it is not quite stabilized until possibly at the age of 6 or shortly after (Clackson et al., 2011; Conroy et al., 2009). However, it is still weak enough to be boosted by relevant consistent information, but nevertheless stable enough not to be overridden by cues that are inconsistent with the event as a whole (including the visual context). The early main effect for fronted objects that quickly faded after the pronoun is in 
line with this as well. This further shows that children, like adults, use the first-mentioned referents as the basis when building a situation model of the event, but are still less able to update the model on the fly when this is required by uncertain/conflicting information, e.g., when the first mentioned entity is not the preferred subject (see Pyykkönen \& Järvikivi, 2012).

A second possibility is that at this stage children simply use different (additional) information than adults, which could require more complex processing, whereas in adults the subjecthood principle could allow for straightforward mapping between the pronoun and the intended referent. However, neither the present nor the previous studies support this. Rather, it seems that focusing helps the children to identify the subject character and add to its perceivable salience, thus making the referential link easier to establish (Almor, 1999; Foraker, 2004; Foraker \& McElree, 2007). This suggests that children were qualitatively similar to adults by treating focus as a salience-enhancing cue for the more discourse salient antecedent. Moreover, the gender effects, preference for subjects, effects of topicalization and verb semantics in the previous literature are all qualitatively in line with adult data (e.g., Hartshorne et al., 2010; Pyykkönen et al., 2010). Thus to assume a differing source of information would need an extra assumption that has no obvious support in the literature. However, since we did not find any clear effect for focus with adults but did find one for children, it is therefore useful to consider potential explanations for this difference. First, it may be that subject clefts are relatively more marked than object clefts: raising an object to first position - cleft or not - already results in a marked constructions and the relative impact of clefting might not add to the salience of objects, unlike with cleft subjects, which are relatively more strongly marked than nonfocused first-position subjects (e.g., Kaiser, 2011; Prince, 1992). Furthermore, assuming that clefting is a focusing device in the constructions under investigation in this paper and that subjects are generally considered as default topics, 
clefting is more informative for subjects than for objects. The default interpretation of the subject as the topic of the sentence needs to be retracted. This is not the case for objects. Clefting subjects is thus more informative from a pragmatic perspective. The fact that subject clefts are more frequent than object clefts, at least in languages where they are used very consistently, confirms their higher pragmatic power (e.g., Lambrecht, 2001). Provided that children are sensitive to the same information as adults, this asymmetry might partly underlie the focus effects on subjects but not on objects in children. It is not clear, however, that it would explain why adults do not show the effect, unless we assume that in adults the referential link to subject referents is so stable that there is no room or need for further increase of availability. Also, recent results from German and French by Colonna et al., (2012) suggest that adults may benefit from clefting when the pronominal reference is between sentences, but not when it is within, as in our case. This raises the second possibility, namely that the children in our study may have interpreted the two clauses as separate sentences. Thirdly, maybe the children had difficulty in interpreting the relative clauses in the clefts. Recently, Brandt, Diessel and Tomasello (2008) argued that 2-5 year-old children's use of relative clause constructions in German, as in many other languages (see Kidd, 2011 for an overview), show a gradual development where they first, at two-years of age, are found in constructions that are very much like simple sentences (e.g., in topicalization) and appear in complex constructions later. Moreover, Brandt, Kidd, Lieven and Tomasello (2009) show that already 3 -year-olds comprehend object and subject relative clauses equally well in a supporting discourse context and especially when the constructions are of the type that they encounter in the input, i.e., the type that they hear from adults frequently in child directed speech. It is thus unlikely that children's lack of knowledge of subordination was why there were no effects on objects, and it is unclear how this account would explain the cleft effects 
on subjects. In sum, all of the above point to the use of the same cues in reference resolution in adults and children the difference being in the ability to use those cues online.

Many previous studies on syntactic ambiguity resolution suggest that children around 4-5 years of age still rely mainly on bottom-up linguistic cues, such as lexical verb information, in processing these structures. In particular, children have been shown to be poorly (or not at all) sensitive to disambiguating contextual information, such as the visual environment or prosody, and unable to revise their initial representations if the contextual information is in contrast with the initial linguistic analysis (e.g., Choi \& Trueswell, 2012; Kidd et al., 2011; Trueswell et al., 1999; Snedeker \& Trueswell, 2004; Weighall, 2008); even though, 4-year-olds do seem to be able to use prosodic information (intonation) to resolve pragmatic ambiguities in an adult-like fashion (zhou et al., 2012) and use prosody to mark and understand information structure cues, like focus (e.g., Sauermann et al., 2011). This seems to point to either the hypothesis that children can take advantage only of a subset of the cues that adults use, relying more on earlier acquired more reliable information, like verb information; or to the possibility that children do weight the same linguistic and nonlinguistic constraints, but are still limited in their cognitive skills that require control in relating the different cues or overriding (more) prominent linguistic cues in the face of conflicting information. This seems to be especially taxing with cross-domain information, whereas with within-domain cues - and with ambiguities that are based on probabilistic constraints as with pronouns - children show an adult-like profile that is quantitatively similar, albeit less clear.

However, it is worth pointing out that these two possibilities are not meant to exhaust all explanations for these observations. Thus, even if children were sensitive to all of the same cues as adults, it is entirely possible that children differ with respect to both how reliable these cues are in the input and limitations in their cognitive control in relating these 
cues in online comprehension. Whether it is one or the other, or both of these, that explain the observed differences in development cannot be resolved by the present study. This is an important topic for future studies that tap into this question directly.

All in all, what is evident from the current data is that neither with adults nor with children does focus change the general preferences, but as the child data suggest, might only act as an enhancing cue to locate the subject antecedent. However, despite this rather strong case for the similarity of constraints with children and adults, a word of caution may be in order: From the available evidence we cannot judge conclusively whether what adults and children react to with respect to cleft structures is based on the same mechanism: namely, it might be that adults react to the implications of focus marking at the level of information structure, whereas children may at this stage of acquisition react to the change in syntactic (or prosodic) weight in terms of extra marking for the relevant noun phrase. However, as the interaction between grammatical role shows, their reaction is nonetheless in order with adult profile, whether due to the same mechanisms or not.

In general, the study is in line with the view that children's language comprehension is subject to similar processes of building the situation model as adults' language comprehension. Pyykkönen and Järvikivi (2012) suggested that the most prominent entity forms the basis of the children's situation model in the same way as with adults, and this primary information is evaluated during the course of processing based on other cues available in the linguistic structure. In German pronoun resolution, the subject can be seen as forming the basis for this process and will thus be most affected by clefting. What might differ between the adult and child comprehenders is their cognitive ability to incrementally update the situation/discourse model: while adults have fully developed cognitive resources to do so, children are still in the course of development and therefore may show the same 
effects, but with a different temporal resolution. However, as we pointed out above, further research is needed to resolve whether this is indeed so.

\section{Conclusion}

The current study showed that very young children are sensitive to fine-grained information structure cues when constructing the situation/discourse model of the events. It seems that already four-year-old children are similar to adults in that they prefer to link an ambiguous personal pronoun to the subject antecedent of the preceding context. When clefted, the subject is highlighted making it easier for the children to make this link, whereas in adults the primary preference is so stable and fast that the benefit is negligible. In other words, the search for a referent is driven by primary constraints like subjecthood. Clefting has a secondary effect, enhancing this process by making it easier for the children to locate the subject.

\section{References}

Almor, A. (1999). Noun-phrase anaphora and focus: the informational load hypothesis. Psychological Review 106, 748-765.

Arnold, J. (1999). Marking Salience: The similarity of topic and focus. Unpublished manuscript, University of Pennsylvania.

Arnold, J. E., Brown-Schmidt, S., \& Trueswell, J. C. (2007). Children's use of gender and order-of-mention during pronoun comprehension. Language and Cognitive Processes $22,527-65$. 
Arnold, J. E., Brown-Schmidt, S., Trueswell, J. C., \& Fagano, M. (2005). Children's use of gender and order of mention during pronoun comprehension. In J. Trueswell \& M. Tanenhaus (Eds.), Approaches to studying world-situated language use (pp. 261281). Cambridge, MA: MIT Press.

Arnold, J.E., Eisenband, J.G., Brown-Schmidt, S., \& Trueswell, J.C. (2000). The rapid use of gender information: Evidence of the time course of pronoun resolution from eyetracking. Cognition, 76, B13-B26.

Baayen, R. H. (2008). Analyzing linguistic data: A practical introduction to statistics using $R$. Cambridge, UK: Cambridge University Press.

Barr, D. (2008). Analyzing 'visual world' eyetracking data using multilevel logistic regression. Journal of Memory and Language, 59, 457-474.

Barsalou, L. W. (1999). Perceptual symbols systems. Behavioural and Brain Sciences, 22, $577-660$.

Birch, S. L., Albrecht, J. E., \& Myers, J. L. (2000). Syntactic focusing structures influence discourse processing. Discourse Processes, 30, 285-304.

Birch, S. L., \& Garnsey, S. (1995). The effect of focus on memory for words in sentences. Journal of Memory and Language, 34, 232-267. 
Birch, S. L., \& Rayner, K. (1997). Linguistic focus affects eye movements during reading. Memory \& Cognition, 25, 653-660.

Bosch, P., Katz, G., \& Umbach, C. (2007). The Non-Subject Bias of German Demonstrative Pronouns. In Schwarz-Friesel, M., Consten, M., \& Knees, M. (Eds.), Anaphors in Text: Cognitive, formal and applied approaches to anaphoric reference, pp. 145-164. Amsterdam: Benjamins.

Bouma, G. \& Hopp, H. (2007). Coreference preferences for personal pronouns in German. In D. Bittner \& N. Gagarina (Eds.), Intersentential pronominal reference in child and adult language,ZASPIL 48, (pp 53-75), Berlin: Zentrum für Allgmeine Sprachwissenschaft.

Brandt, S., Diessel, H., \& Tomasello, M. (2008). The acquisition of German relative clauses: A case study. Journal of Child Language, 35, 325-348.

Brandt, S., Kidd, E., Lieven, E., \& Tomasello, M. (2009). The discourse bases of relativization: An investigation of young German and English speaking children's comprehension of relative clauses. Cognitive Linguistics, 20, 539-570.

Carpenter, P. A., \& Just, M. A. (1977). Reading comprehension as eyes see it. In M. A. Just \& P. A. Carpenter (Eds.), Cognitive processes in comprehension. Hillsdale, NJ: Erlbaum. 
Carreiras, M., Gernsbacher, M.A., \& Villa, V. (1995). The advantage of first mention in Spanish. Psychonomic Bulletin \& Review, 2, 124-129.

Chafe, W.L. (1976). Givenness, contrastiveness, definiteness, subjects, and topics and point of view. In C. Li (Ed.) Subject and topic (pp. 27-55). New York: Academic Press.

Choi, Y., \& Trueswell, J. C. (2010). Children's (in)ability to recover from garden-paths in a verb-final language: Evidence for developing control in sentence processing. Journal of Experimental Child Psychology, 106, 41-61.

Colonna, S., Schimke, S. \& Hemforth, B. (2012). Information structure effects on anaphora resolution in German and French: A cross-linguistic study of pronoun resolution. Linguistics, 50(5), 991-1013.

Colonna, S., Schimke, S. Medam, T. \& Hemforth, B. (2012). Different effects of focus in intra- and inter-sentential pronoun resolution in German and French. Poster presented at the25th Annual CUNY Conference on Human Sentence Processing, New York, 1416 March, 2012.

Conroy, A., Takahashi, E., Lidz , J. \& Phillips, C. (2009). Equal Treatment for All Antecedents: How Children Succeed with Principle B. Linguistic Inquiry, 40, 446486.

Cowles, H.W., Walenski, M., \& Kluender, R. (2007). Linguistic and cognitive prominence in anaphor resolution: Topic, contrastive focus and pronouns. Topoi, 26, 3-18. 
Dittmar, M., Abbot-Smith, K., Lieven, E., \& Tomasello, M. (2008). German children's comprehension of word order and case marking in causative sentences. Child Development, 79, 1152-1167.

Dowty, D. (1991). Thematic roles and argument selection. Language, 67, 547-619.

Drenhaus, H., Zimmermann, M., \&Vasishth, S. (2011). Exhaustiveness effects in clefts are not truth-functional. Journal of Neurolinguistics, 24, 320-337.

Dufter, A. (2007). Clefting and discourse organization: Comparing Germanic and Romance. In Dufter, A. \& Jacob, D. (Eds.), Focus and Background in Romance Languages, pp. 83-121. Amsterdam: Benjamins.

É. Kiss, K. (1998). Identificational Focus versus Information Focus. Language 74, 245-273.

Ellert, M. (2010). Ambiguous pronoun resolution in L1 and L2 German and Dutch. MPI Series in Psycholinguistics, 58. Wageningen: Ponsen \& Looijen.

Fischer, K. (2009). Cleft sentences: Form, function, and translation. Journal of Germanic Linguistics, 21, 167-191.

Foraker, S. (2004). The mechanisms involved in the prominence of referent representations during pronoun coreference (Doctoral dissertation, New York University, 2004). UMI ProQuest Digital Dissertations. 
Foraker, S., \& McElree, B. (2007). The role of prominence in pronoun resolution: Active versus passive representations. Journal of Memory \& Language, 56, 357-383.

Frank, R. (1998). Structural Complexity and the Time Course of Grammatical Development. Cognition 66, 249-301.

Gernsbacher, M. A. (1990). Language comprehension as structure building. Hillsdale, NJ: Lawrence Erlbaum.

Gernsbacher, M.A., \& Hargreaves, D.J. (1988). Accessing sentence participants: The advantage of first mention. Journal of Memory and Language, 27, 699-717.

Gernsbacher, M.A., Hargreaves, D.J., \& Beeman, M. (1989). Building and accessing clausal representations: The advantage of first mention versus the advantage of clause recency. Journal of Memory and Language, 28, 735-755.

Gundel, J. K., Hedberg, N., \& Zacharaski, R. (1993). Cognitive status and the form of referring expressions. Language, 69, 274-307.

Hartshorne, J. K., Nappa, R., \& Snedeker, J. (2010). Ambiguous pronoun processing development: Probably not u-shaped. Proceedings of the 35th annual Boston University Conference on Language Development. Cascadilla Press. 
Hedberg, N. (In Press). Multiple Focus and Cleft Sentences. In Haida, A., Veenstra, T., \& Hartmann, K. (Eds.) The Structure of Clefts. Amsterdam :John Benjamins.

Hemforth, B., Konieczny, L., Scheepers, C., Colonna, S., Schimke, S., \& Pynte, J. (2010). Language specific preferences in anaphor resolution: Exposure or gricean maxims? In Proceedings of the $32^{\text {nd }}$ Annual Conference of the Cognitive Science Society, Portland, USA, August 11-14.

Hopper, P. J., \& Thompson, S. A. (1980). Transitivity in grammar and discourse. Language, $56,25-299$.

Hornby, P. A. (1974). Surface structure and presupposition. Journal of Verbal Learning and Verbal Behavior, 13, 530-538.

Jaeger, F. (2008). Categorical data analysis: Away from ANOVAs (transformation or not) and towards logit mixed models. Journal of Memory and Language, 59, 434-446.

Jaeger, T. F., \& Snider, N. (2008). Implicit learning and syntactic persistence: Surprisal and cumulativity. Proceedings of the 30th Annual Meeting of the Cognitive Science Society, $827-812$.

Järvikivi, J., van Gompel, R. P. G., Hyönä, J., \& Bertram, R. (2005). Ambiguous pronoun resolution: contrasting the first-mention and subject-preference accounts. Psychological Science, 16(4), 260-264. 
Kaiser, E. (2011). Focusing on pronouns: Consequences of subjecthood, pronominalization and contrastive focus. Language and Cognitive Processes, 26, 1625-1666.

Kehler, Andy. 2002. Coherence, Reference and the Theory of Grammar. Stanford, CA: CSLI Publications.

Keijzer, M. (2007). Last in First out? An investigation of the regression hypothesis in Dutch emigrants in Anglophone Canada. Vrije Universiteit Amsterdam. PhD Dissertation.

Kidd, E. (Ed.) (2011). The Acquisition of Relative Clauses: Processing, typology and function. Amsterdam: Benjamins.

Kidd, E., Stewart, A. J., \& Serratrice, L. (2011). Children do not overcome lexical biases where adults do: The role of the referential scene in garden-path recovery. Journal of Child Language, 38, 222-234.

Koornneef, A. W., \& Van Berkum, J. J. A. (2006). On the use of verb-based implicit causality in sentence comprehension: Evidence from self-paced reading and eye tracking. Journal of Memory and Language, 54, 445-465.

Krifka, M. (2007). Basic notions of information structure. In Féry, C., \& Krifka, M. (Eds.), Interdisciplinary Studies of Information Structure 6, Working Papers of the SFB632, pp. 13-56. Potsdam: Universitätsverlag Potsdam. 
Lambrecht, K. (2001). A framework for the analysis of cleft constructions. Linguistics,39, $463-516$.

MacWhinney, B. (1977). Starting points. Language, 53, 152-168.

Matin, E., Shao, K., \& Boff, K. (1993). Saccadic overhead: information processing time with and without saccades. Perceptual Psychophysics, 53, 372-380.

McDonald, J. L., \& MacWhinney, B. J. (1995). The time course of anaphor resolution: Effects of implicit verb causality and gender. Journal of Memory and Language, 34, $543-566$.

Novick, J.M., Trueswell, J.C. \& Thompson-Schill, S.L. (2005). Cognitive Control and Parsing: Reexamining the Role of Broca's Area in Sentence Comprehension. Cognitive, Affective, \& Behavioral Neuroscience, 5, 263-281.

Prince, E. F. (1992). The ZPG letter: subjects, definiteness, and information status. In SThompson and W. Mann (Eds.), Discourse description: diverse analyses of a fundraising text (pp. 295-325). Amsterdam: Benjamins.

Pyykkönen, P. \& Järvikivi, J. (2010). Activation and persistence of implicit causality information in spoken language comprehension. Experimental Psychology, 57, 5-16.

Pyykkönen, P. \& Järvikivi, J. (2012). Children and situation models of multiple events. Developmental Psychology, 48, 521-529. 
Pyykkönen, P., Matthews, D., \& Järvikivi, J. (2010). Three-year-olds are sensitive to semantic prominence during online language comprehension: A visual world study of pronoun resolution. Language and Cognitive Processes, 25, 115-129.

Sauermann, A., Höhle, B., Chen, A., \& Järvikivi, J. (2011). Intonational marking of focus in different word orders in German children. In M. Byram Washburn, K. McKinneyBock, E. Varis, A. Sawyer, \& B. Tomaszewicz (Eds.), Proceedings of the $28^{\text {th }}$ West Coast Conference on Formal Linguistics. Somerville, MA: Cascadilla Press, 313322.

Sekerina, I. A., Stromswold, K., \& Hestvik, A. (2004). How do adults and children process referentially ambiguous $\square$ pronouns? Journal of Child Language, 31(1), 123-152.

Singer, M. (1976). Thematic structure and the integration of linguistic information. Journal of Verbal Learning and Verbal Behavior, 15, 549-558.

Snedeker, J., \& Trueswell, J. C. (2004). The developing constraints on parsing decisions: The role of lexical-biases and referential scenes in child and adult sentence processing. Cognitive Psychology, 49, 238-299.

Sturt, P., Sanford, A. J., Stewart, A., and Dawydiak, E. (2004). Linguistic focus and goodenough representations: an application of the change-detection paradigm. Psychonomic Bulletin and Review, 11, 882-888. 
Song, H., \& Fisher, C. (2006). Who's "she"? Discourse structure influences preschoolers' pronoun interpretation. Journal of Memory \& Language, 52(1), 29-57.

Song, H., \& Fisher, C. (2007). Discourse prominence effects on 2.5-year-old children's interpretation of pronouns. Lingua, 117, 1959-1987.

Trueswell, J. C., Sekerina, I., Hill, N., \& Logrip, M. (1999). The kindergarten-path effect: Studying on-line sentence processing in young children. Cognition, 73, 89-134.

Van Berkum, J. J. A., Koornneef, A. W., Otten, M., \& Nieuwland, M. S. (2007). Establishing reference in language comprehension: An electrophysiological perspective. Brain Research, 1146, 158-171.

Ward, P. and Sturt, P. (2007). Linguistic focus and memory: an eye-movement study. Memory and Cognition, 35, 73-86.

Zimmer, H. D. \& Engelkamp, J. (1981). The given-new structure of cleft sentences and their influence on picture viewing. Psychological Research, 43, 375-389.

Weighall, A. R. (2008). The kindergarten-path effect revisited: Children's use of context in processing structural ambiguities. Journal of Experimental Child Psychology, 99, 7595.

Weighall, A. R., Altmann, G. T. M. (2011). The role of working memory and contextual constraints in children's processing of relative clauses. Journal of Child Language, 
Focus in children's reference comprehension

$38,579-605$.

Zwaan, R.A. (2004). The immersed experiencer: toward an embodied theory of language comprehension. In: B.H. Ross (Ed.), The Psychology of Learning and Motivation, Vol. 44 (pp. 35-62). New York: Academic Press.

Zwaan, R.A., \& Madden, C.J. (2004). Updating situation models. Journal of Experimental Psychology: Learning, Memory, and Cognition, 30, 283-288.

Zwaan, R.A., \& Radvansky, G.A. (1998). Situation models in language comprehension and memory. Psychological Bulletin, 123, 162-185. 
Focus in children's reference comprehension

\section{Footnotes}

1. According to Dufter (2007), while often used in present-day German, it-clefts in German are much less frequent than their translational counterparts in Romance languages. While there is some recent evidence, that adults process these semantic and pragmatic aspects of clefts online (Drenhaus, Zimmermann, \& Vasishtsh, 2010), to our knowledge the full semantic interpretation of clefts has not yet been studied in children.

2. Only referents with the grammatical gender masculine were used, because masculine nouns are morphologically marked for (subject and object) case (nominative, accusative) and number (singular, plural) in German. Note however, the pronoun er 'he' was used ambiguously to refer to either of the animals in the sentences.

3. Previous research has shown that it takes approximately $200 \mathrm{~ms}$ to plan and execute a saccade (Matin, Shao, \& Boff, 1993). Therefore, in order to allow for this we started the analyses $200 \mathrm{~ms}$ after the pronoun onset.

4. Analogous analyses for the adult data indeed showed significantly more looks to subject antecedents overall, but no other effects in all three $600 \mathrm{~ms}$ time segments. The models are available from the authors in request.

5. Further analysis on the $2000-2600 \mathrm{~ms}$ time window shows a preference for subject referents (estimate $=0.2056, \mathrm{z}=2.050, \mathrm{P}=0.0430$ ) but no effect of focus (estimate $=$ 0.0191, $\mathrm{z}=0.229, \mathrm{P}=0.819$ ) showing an overall subject preference for children but one that arises considerably later than in adults. 
Focus in children's reference comprehension

Acknowledgements

This study was carried out while the first author was at the Max Planck Institute for Psycholinguistics, Nijmegen, The Netherlands. We would like to thank: Laura de Ruiter for her voice, Johanna Tewes and Alexa Weiss for their help in preparing and administering the experiments; Kindergartens Regenbogen, St. Lambertus, St. Willibrord and Zauberfarben in Kleve and St. Barbara in Kranenburg for participation in the study. 
Focus in children's reference comprehension

Tables

Table 1.

Example of the Materials and Conditions. The column "Scene" refers to Figure 1.

\begin{tabular}{|c|c|c|}
\hline Condition & Context, antecedent and pronoun sentences & Scene \\
\hline & Da sind der Hase und der Fuchs/Fuchs und der Hase & A \\
\hline No Cleft - SVO & $\begin{array}{l}\text { Der Hase kitzelt den Fuchs, } \\
\text { 'The rabbit tickles the fox, ' }\end{array}$ & $\mathrm{B}$ \\
\hline No Cleft - OVS & $\begin{array}{l}\text { Den Fuchs kitzelt der Hase, } \\
\text { 'The fox (Obj) tickles the rabbit (sub)' }\end{array}$ & $\mathrm{B}$ \\
\hline $\begin{array}{l}\text { Cleft - SVO } \\
\text { (Subject focus) }\end{array}$ & $\begin{array}{l}\text { Es ist der Hase, der den Fuchs kitzelt, } \\
\text { 'It is the rabbit, who tickles the fox' }\end{array}$ & $\mathrm{B}$ \\
\hline $\begin{array}{l}\text { Cleft - OVS } \\
\text { (Object focus) }\end{array}$ & $\begin{array}{l}\text { Es ist der Fuchs, den der Hase kitzelt, } \\
\text { 'It is the fox, whom tickles the rabbit' }\end{array}$ & $\mathrm{B}$ \\
\hline & $\begin{array}{l}\text { an dem Bergsee, als } \boldsymbol{e r} \text { gerade an etwas ganz besonders } \\
\text { lustiges denkt. } \\
\text { 'at the mountain lake' 'when he just about something } \\
\text { particularly funny thinks' }\end{array}$ & A \\
\hline & $\begin{array}{l}\text { Doch dann muß der Hase plötzlich ganz furchtbar } \\
\text { weinen. } \\
\text { 'But then the rabbit suddenly rather terribly cries.' }\end{array}$ & $\mathrm{C}$ \\
\hline
\end{tabular}


Focus in children's reference comprehension

Table 2.

The overall model with the best fit to the data for the time segment 200-2000ms from the onset of the pronoun. The reference levels (intercept terms) for the fixed-effects predictors were as follows: Focus - noncleft; (Grammatical) Role - Object; Group-Adults.

\begin{tabular}{lllll}
\hline Fixed Effects & Estimate & Std.Error & Wald-Z & $p$-value \\
\hline & 1.7167 & 0.0781 & 21.959 & $0.0000^{* * *}$ \\
(Intercept) & & & & \\
Focus(Cleft) & 0.0259 & 0.0161 & 1.609 & 0.1077 \\
Role(Subject) & -0.0067 & 0.0813 & -0.083 & 0.9341 \\
Group(Adults) & -0.0615 & 0.1100 & -0.560 & 0.5756 \\
Focus:Role & 0.1187 & 0.0225 & 5.263 & $0.0000^{* * *}$ \\
Focus:Group & -0.0271 & 0.0244 & -1.113 & 0.2658 \\
Role:Group & 0.3421 & 0.1213 & 2.818 & $0.0048^{* *}$ \\
Focus:Role:Group & -0.1163 & 0.0330 & -3.521 & $0.0004^{* * *}$ \\
\hline Note:
\end{tabular}

Note: $(*) \mathrm{p}<.1,{ }^{*} \mathrm{p} \leq .05, * * \mathrm{p}<.01, * * * \mathrm{p}<.001$ 
Table 3.

The models with the best fit to the data from the children in three consecutive 600ms time windows. The reference levels (intercept terms) for the fixed-effects predictors were as follows: Focus - noncleft; Grammatical Role-Object.

\begin{tabular}{lllll}
\hline Fixed Effects & Estimate & Std.Error & Wald-Z & $\boldsymbol{p}$-value \\
\hline $\mathbf{2 0 0 - 8 0 0 m s}$ & & & & \\
(Intercept) & 0.5367 & 0.0921 & 5.828 & $0.0000^{* * * *}$ \\
Focus(Cleft) & 0.0103 & 0.0286 & 0.358 & 0.720 \\
Role(Subject) & -0.251 & 0.1003 & -2.509 & $0.012^{*}$ \\
Focus:Role & 0.2793 & 0.0417 & 6.700 & $0.0000^{* * *}$ \\
& & & & \\
$\mathbf{8 0 0 - 1 4 0 0 m s}$ & & & & \\
(Intercept) & 0.6158 & 0.1007 & 6.115 & $0.0000^{* * * *}$ \\
Focus(Cleft) & 0.0165 & 0.0274 & 0.601 & 0.548 \\
Role(Subject) & -0.0213 & 0.0991 & 0.830 & 0.830 \\
Focus:Role & 0.1489 & 0.0381 & 3.907 & $0.0000^{* * * *}$ \\
& & & & \\
1400-2000ms & & & & $0.0000^{* * * *}$ \\
(Intercept) & 0.5944 & 0.0773 & 7.688 & $0.0688\left(^{*}\right)$ \\
Focus(Cleft) & 0.0509 & 0.0280 & 1.820 & 0.230 \\
Role(Subject) & 0.1465 & 0.1104 & 1.327 & \\
& & & & \\
\hline
\end{tabular}

Note: $(*) p<.1, * p \leq .05, * * p<.01, * * * p<.001$ 
Focus in children's reference comprehension

Figure captions

Figure 1. Schematic Representation of the Scenes Used in the Experimental Video Clips.

Panels A, B, and C correspond to Example Sentences Listed in Table 1.

Figure 2. Percent of Fixations to the Antecedent Pictures by Grammatical Role (Subject, Object) and Focus (Clefted, Nonclefted) as a Function of Time Starting 200 Milliseconds Before the Onset of the Pronoun. Panel A: Children; Panel B: Adults. 
Focus in children's reference comprehension

A

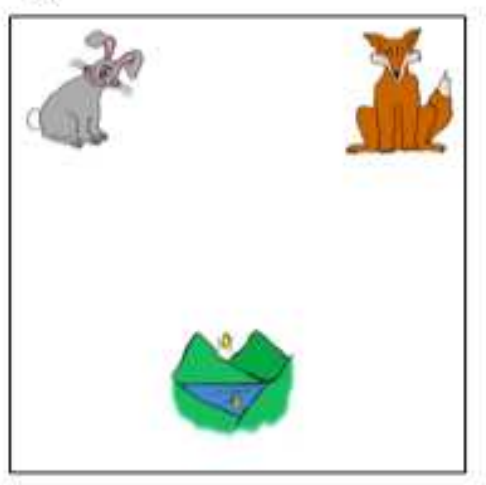

B

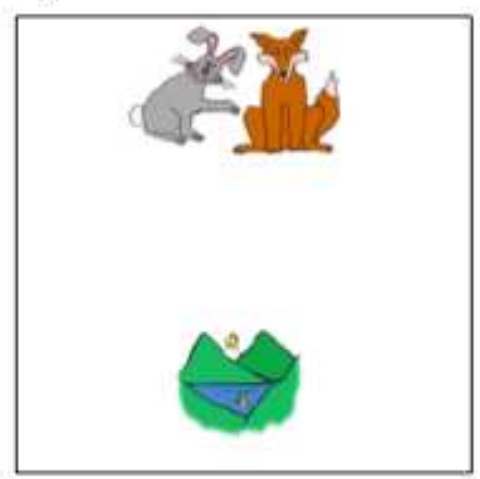

C

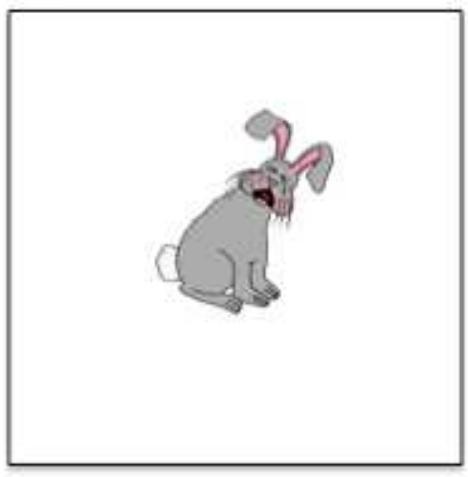




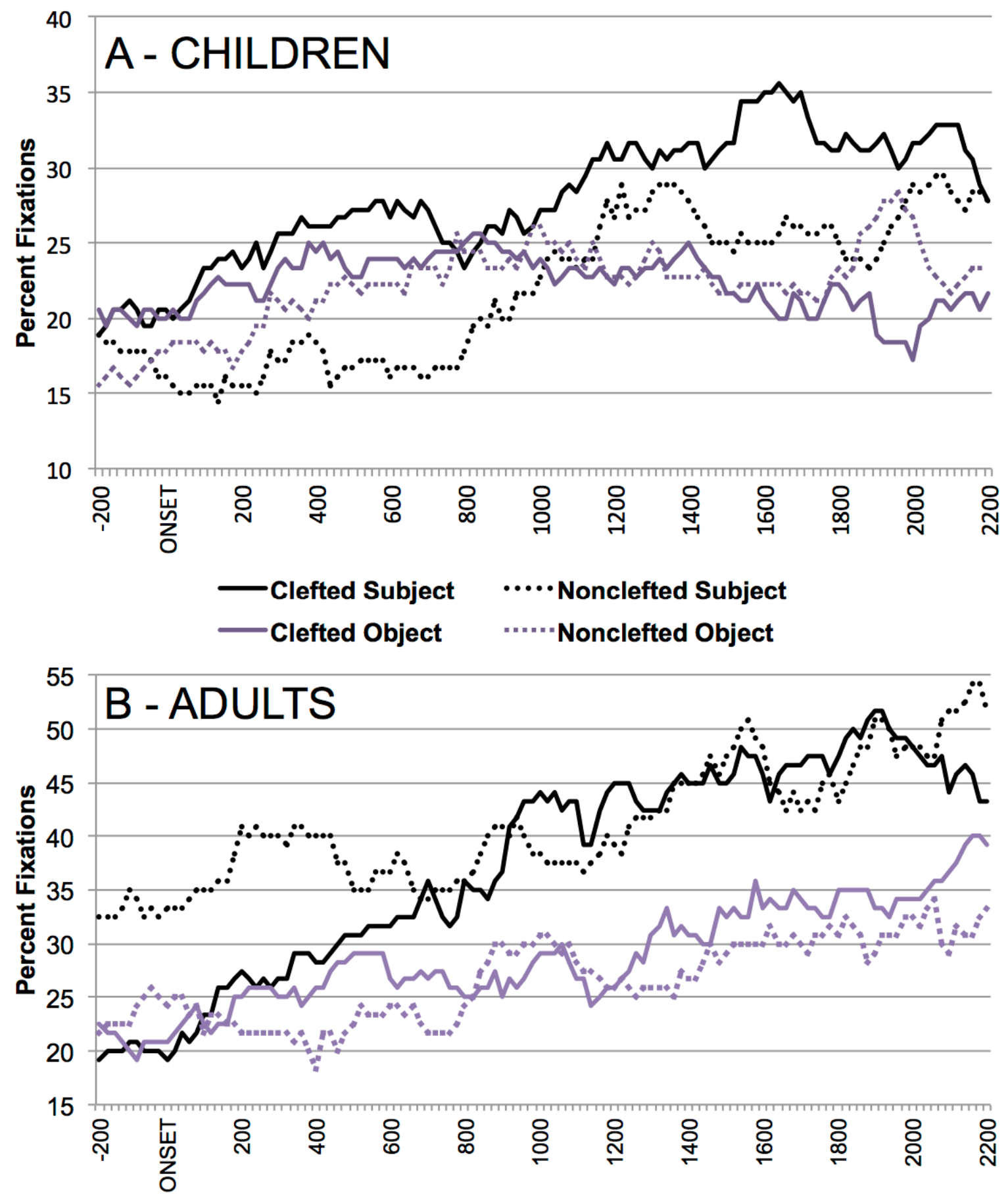


Appendix A

Animal Characters and Verbs Used in the Experimental and Filler Materials.

\begin{tabular}{llll}
\hline Subject character & Object character & Verb & Status \\
\hline Der Hase (Rabbit) & Der Fuchs & Kitzeln (Tickle) & Exp \\
Der Fuchs (Fox) & Der Hase & Kneifen (Pinch) & Exp \\
Der Fisch (Fish) & Der Seehund & Hauen (Hit) & Exp \\
Der Seehund (Seal) & Der Fisch & Küssen (Kiss) & Exp \\
Der Delfin (Dolphin) & Der Tintenfisch & Beissen (Bite) & Exp \\
Der Tintenfisch (Squid) & Der Delfin & Kitzeln (Tickle) & Exp \\
Der Affe (Monkey) & Der Tiger & Schlagen (Hit) & Exp \\
Der Tiger (Tiger) & Der Affe & Drücken (Squeeze) & Exp \\
Der Papagei (Parrot) & Der Pinguin & Streicheln (Stroke) & Exp \\
Der Pinguin (Penguin) & Der Papagei & Treten (Kick) & Exp \\
Der Hund (Dog) & Der Bär & Streicheln (Stroke) & Exp \\
Der Bär (Bear) & Der Hund & Hauen (Hit) & Exp \\
Der Panda (Panda) & Der Ziegenbock & Drücken (Squeeze) & Exp \\
Der Ziegenbock (Goat) & Der Panda & Küssen (Kiss) & Exp \\
Der Loewe (Lion) & Der Drache & Kratzen (Scratch) & Exp \\
Der Drache (Dragon) & Der Loewe & Treten (Kick) & Exp \\
Der Biber (Beaver) & Der Wal & Kneifen (Pinch) & Exp \\
Der Wal (Whale) & Der Biber & Beissen (Bite) & Exp \\
Der Frosch (Frog) & Der Marienkäfer & Kratzen (Scratch) & Exp \\
Der Marienkäfer (Ladybird) & Der Frosch & Schlagen (Hit) & Exp \\
Das Schwein (Pig) & Das Kuh & Schubsen (Push) & Filler \\
Das Kuh (Cow) & Das Schwein & Pieken (Prick) & Filler \\
Die Spinne (Spider) & Die Katze & Pieken (Prick) & Filler \\
Die Katze (Cat) & Die Spinne & Knuddeln (Hug) & Filler \\
Das Pferd (Horse) & Das Schaf & Boxen (Box/Hit) & Filler \\
Das Schaf (Sheep) & Das Pferd & Umarmen (Hug) & Filler \\
Das Zebra (Zebra) & Die Giraffe & Umarmen (Hug) & Filler \\
Die Giraffe (Giraffe) & Das Zebra & Boxen (Box/hit) & Filler \\
Die Maus (Mouse) & Die Ente & Knuddeln (Hug) & Filler \\
Die Ente (Duck) & Die Maus & Schubsen (Push) & Filler \\
\hline
\end{tabular}

